\title{
Long-term outcome of congenital aortic valve stenosis: predictors of reintervention
}

\author{
Léa Hochstrasser, ${ }^{1}$ Patrick Ruchat, ${ }^{1}$ Nicole Sekarski, ${ }^{2}$ Michel Hurni, ${ }^{1}$ Ludwig K. von Segesser ${ }^{1}$ \\ ${ }^{1}$ Department of Cardiovascular Surgery, University Hospital, Lausanne, Switzerland; ${ }^{2}$ Pediatric Cardiology Unit, \\ University Hospital, Lausanne, Switzerland
}

\begin{abstract}
Objectives: To evaluate long-term outcome of initial aortic valve intervention in a paediatric population with congenital aortic stenosis, and to determine risk factors associated with reintervention. Patients and methods: From 1985 to 2009,77 patients with congenital aortic stenosis and a mean age of $5.8 \pm 5.6$ years at diagnosis were followed up in our institution for $14.8 \pm 9.1$ years. Results: First intervention was successful with $86 \%$ of patients having a residual peak aortic gradient $<50 \mathrm{mmHg}$, and the proportion of patients with grade $>1$ regurgitation increased by $7 \%$. Long-term survival after the first procedure was excellent, with $91 \%$ survival at 25 years. At a mean interval of $7.6 \pm 5.3$ years, 30 patients required a reintervention (39\%), mainly because of a recurrent aortic stenosis. Freedom from reintervention was 97, 89, 75, 53, and 42\% at 1, 10, 15, 20, and 25 years, respectively. Predictors of reintervention were residual peak aortic gradient $(\mathrm{p}=0.0001)$, aortic regurgitation post-intervention $>1(\mathrm{p}=0.02)$, prior balloon aortic valvuloplasty $(\mathrm{p}=0.04)$, and increased left ventricular posterior wall thickness $(\mathrm{p}=0.1)$. Conclusions: Aortic valve intervention is a safe and effective procedure for congenital aortic stenosis with excellent survival results. However, rate of reintervention is high and influenced by increased left ventricular posterior wall thickness pre-intervention, prior balloon valvuloplasty, higher residual peak systolic valve gradient, and more than mild regurgitation post-intervention. The study highlights that long-term follow-up is recommended for these patients.
\end{abstract}

Keywords: Congenital aortic valve stenosis; balloon valvuloplasty; surgical valvotomy; predictors of reintervention

Received: 5 January 2014; Accepted: 24 May 2014; First published online: 1 July 2014

A ORTIC VALVE STENOSIS IS THE MOST FREQUENT valvular heart disease and represents $2-5 \%$ of all congenital heart anomalies. ${ }^{1-2}$ The natural history of congenital aortic valve stenosis is well documented and described as a progressive lesion with high risk of sudden cardiac death. The overall 25 -year survival in aortic valve stenosis is $85 \%$ with $59 \%$ of patients ultimately requiring intervention. ${ }^{3}$ Surgical aortic valvotomy, introduced by Lillehei in 1956 , was the only therapeutic option until 1983, when Lababidi introduced the aortic balloon valvotomy. ${ }^{4-5}$ Nowadays, both techniques show comparable early results, ${ }^{6-9}$ and the choice of treatment seems to vary

Correspondence to: L. Hochstrasser, Walchestrasse 27, CH-8006 Zürich, Switzerland. Tel: +0041 7891322 44; Fax: +0041 2131436 65; E-mail: hochstrasserlea @gmail.com more according to local expertise and/or preference as well as the age of the patient. Owing to restenosis or residual regurgitation, the first intervention is often palliative and reintervention is necessary sooner or later. In the literature, $85-95 \%$ of children and young adults are free of reintervention for at least 10 years. At 20 and 40 years after initial intervention, only 60 and $10 \%$ of patients will be free of reintervention, respectively. ${ }^{2}$

Predicting long-term outcomes of patients with congenital aortic stenosis has proven to be a clinical challenge, largely because mechanism of restenosis and residual regurgitation is not well known. The purpose of this retrospective study is to describe the long-term outcomes of aortic valve stenosis during a 25-year follow-up, and to investigate early and late determinant factors of reintervention. 


\section{Materials and methods}

\section{Patient selection}

All patients $<16$ years of age with a congenital narrowing of the aortic valve were identified as patients with a congenital aortic stenosis. The follow-up took place from January 1985 to December 2009 in our institution. At least, pre- and post-intervention medical data and echocardiographic examinations were required to be included. Exclusion criteria were any other associated cardiac malformations influencing the decision to operate on the heart. During the 25-year follow-up, a total of 167 patients were identified; of them, 57 were excluded because of documented associated malformations or incomplete medical data and of the 110 patients left, 77 underwent an intervention and were eligible for the study.

For the statistical analysis and the determination of predictors of reintervention, the 77 patients were divided into two groups: a group of patients with intervention and no reintervention (group A); and a group of patients with intervention and reintervention (group B).

Ethical approval and data collection was obtained according to the guidelines of the ethical committee for clinical research of our University Hospital.

\section{Clinical data}

Patients were identified using the medical and echocardiographic database. Variables included demographic information, clinical status, echocardiographic, and haemodynamic data reviewed by the same investigator. We defined the clinical status as "normal" in asymptomatic patients, and as "reduced" in patients with symptoms of dyspnoea, syncope, angina pectoris, fatigue on exertion, cardiogenic shock, left ventricular strain on the ECG, low cardiac output, and severe left ventricular dysfunction. End-points were defined as aortic valve intervention, reintervention, and death during follow-up.

\section{Echocardiographic data}

All standard echocardiographic examinations were conducted without sedation by a paediatric cardiologist. Left ventricular morphologic criteria were derived from M-mode analysis. As cardiac dimensions and body surface change non-linearly during normal growth and development, the Haycock formula of body surface area was used to index these recorded parameters: left ventricular end-systolic and end-diastolic diameter, interventricular septum thickness, left ventricular posterior wall thickness, and aortic annulus diameter. ${ }^{10}$ Moreover, these variables were standardised according to the Z-score, to enhance comparison between individuals. ${ }^{11}$ The aortic jet velocity was recorded with continuous-wave Doppler and used to calculate the peak aortic gradient. ${ }^{12}$ In our institution and according to the guidelines, ${ }^{13}$ a peak aortic gradient $>50 \mathrm{mmHg}$ in symptomatic patients and a peak aortic gradient $>60 \mathrm{mmHg}$ in asymptomatic patients were indicators for intervention. On the basis of colour flow imaging, aortic regurgitation severity was graded from none to severe (grade 0-3).

The bicuspid valve is defined as an aortic valve formed of two leaflets or functioning like a two-leaflet valve. The denomination dysplasia is defined by using a standardised system developed in this study including thickening, fibrosis, or hypoplasia of the valve leaflets.

\section{Statistical analysis}

All statistical analyses were performed using Statistical Analysis Software JPM version 8.02 (SAS Institute, Cary, New Jersey, United States of America). Univariate analysis with the parametric tests (paired t-test, $\chi^{2}$-test, or Pearson regression) was performed to identify differences between categories of possible predictors compared with the end-points: intervention, reintervention, and death. The mean and standard deviations were derived for the continuous variables. Categorical variables were expressed as counts and percentages. Multivariate analysis was performed using stepwise multiple linear regressions to determine independent predictors of reintervention. Variables with a p-value 0.10 in the univariate analysis were included in the stepwise multivariable fit model. Kaplan-Meier survival analysis was used to estimate probabilities of reintervention-free survival rates for the levels of various prognostic factors, and to estimate the overall survival rates from the time of admission to death. For patients who did not reach end-point death, the data were censored at the time of hospital discharge, last echocardiographic examination recorded, or at the time of end of the study. Risk ratio and $95 \%$ confidence intervals were calculated using a Cox proportional hazards model. A p-value $<0.05$ was considered as statistically significant.

\section{Results}

\section{Characteristics of patients}

From January, 1985 to December, 2009, 77 patients who underwent intervention with congenital aortic valve stenosis were identified with a majority of male patients $(n=51,66 \%)$ (Table 1$)$. The mean age of the cohort was $5.8 \pm 5.6$ years. At diagnosis, 29 patients were $<1$ year old $(38 \%)$, and 11 patients were $<1$ month old (14\%). A bicuspid aortic valve was found in 56 patients (73\%), a tricuspid valve in $20(26 \%)$, and a unicuspid valve in one patient (1\%). A muscular or fibromuscular subvalvular stenosis was associated in 17 cases (22\%). A total of 49 patients 
Table 1. Baseline patient characteristics.

\begin{tabular}{|c|c|c|c|}
\hline & Total & $\begin{array}{l}\text { Intervention with no } \\
\text { reintervention (group A) }\end{array}$ & $\begin{array}{l}\text { Intervention with } \\
\text { reintervention (group B) }\end{array}$ \\
\hline Number of patients & 77 & 47 & 30 \\
\hline Age at diagnosis (months) & $69.7 \pm 67.1$ & $80.6 \pm 68.7$ & $52.6 \pm 62.1$ \\
\hline Patients with age at diagnosis $<1$ year & $29(38 \%)$ & $14(30 \%)$ & $15(50 \%)$ \\
\hline Patients with age at diagnosis $<1$ month & $11(14 \%)$ & $7(15 \%)$ & $4(13 \%)$ \\
\hline Median body length $(\mathrm{cm})$ & 101.3 & $107.1 \pm 39.9$ & $92.2 \pm 33.6$ \\
\hline Median body weight $(\mathrm{kg})$ & 20.6 & $23.3 \pm 17.8$ & $16.4 \pm 12.8$ \\
\hline \multicolumn{4}{|l|}{ Gender ratio } \\
\hline Male & $51(66 \%)$ & $31(66 \%)$ & $20(67 \%)$ \\
\hline Female & $26(34 \%)$ & $16(34 \%)$ & $10(33 \%)$ \\
\hline \multicolumn{4}{|l|}{ Morphology valve } \\
\hline Tricuspid & $20(26 \%)$ & $11(23 \%)$ & $9(30 \%)$ \\
\hline Bicuspid & $56(73 \%)$ & $36(77 \%)$ & $20(67 \%)$ \\
\hline Unicuspid & $1(1 \%)$ & & $1(3 \%)$ \\
\hline None associated pathologies & $49(64 \%)$ & $30(64 \%)$ & $19(63 \%)$ \\
\hline Subvalvular stenosis & $17(22 \%)$ & $11(23 \%)$ & $6(20 \%)$ \\
\hline Dysplastic aortic valve & $49(64 \%)$ & $30(64 \%)$ & $19(63 \%)$ \\
\hline \multicolumn{4}{|l|}{ Number of interventions } \\
\hline One & $77(100 \%)$ & & \\
\hline Two (reintervention) & $30(39 \%)$ & & \\
\hline Three & $7(9 \%)$ & & \\
\hline Four & $2(3 \%)$ & & \\
\hline \multicolumn{4}{|l|}{ First intervention type } \\
\hline Balloon & $22(29 \%)$ & $7(15 \%)$ & $15(50 \%)$ \\
\hline Valvotomy & $42(55 \%)$ & $28(60 \%)$ & $14(47 \%)$ \\
\hline Ross & $6(8 \%)$ & $6(13 \%)$ & 0 \\
\hline AVR & $6(8 \%)$ & $5(11 \%)$ & $1(3 \%)$ \\
\hline Homograft & $1(1 \%)$ & $1(2 \%)$ & 0 \\
\hline \multicolumn{4}{|l|}{ First reintervention type } \\
\hline Balloon & & & 0 \\
\hline Valvotomy & & & $5(17 \%)$ \\
\hline Ross & & & $19(63 \%)$ \\
\hline AVR & & & $6(20 \%)$ \\
\hline \multicolumn{4}{|l|}{ Homograft } \\
\hline Death total & $6(8 \%)$ & $4(9 \%)$ & $2(7 \%)$ \\
\hline Death $>30$ days after the intervention & $3(4 \%)$ & $2(4 \%)$ & $1(3 \%)$ \\
\hline
\end{tabular}

AVR $=$ aortic valve replacement

(64\%) had an aortic valve dysplasia with fibrotic, thickened, or hypoplastic leaflets. The majority of the patients $(n=55,71 \%)$ were symptomatic at diagnosis (Table 2), with 14 patients <1 year of age $(18 \%)$ showing symptoms of congestive heart failure, such as dyspnoea or fatigue on exertion.

The mean peak aortic gradient before intervention was evaluated at $92 \pm 30 \mathrm{mmHg}$; more precisely, 75 patients (97\%) had a peak aortic gradient $>50 \mathrm{mmHg}, 69(90 \%)$ had a gradient $>60 \mathrm{mmHg}$, and $57(74 \%)$ had a gradient $>75 \mathrm{mmHg}$. At the time of intervention, 67 patients $(87 \%)$ had no or mild aortic regurgitation (grade 0-1). Signs of left ventricular hypertrophy with strain on ECG were found in three patients (3\%).

\section{Immediate results}

The initial intervention was a surgical aortic valvotomy in 42 patients (55\%), a percutaneous balloon aortic valvuloplasty in 22 patients (29\%), a Ross procedure in six patients (8\%), an aortic valve replacement in six patients $(8 \%)$, and an aortic homograft replacement in one patient $(1 \%)$.

The mean residual peak systolic valve gradient was $35 \mathrm{mmHg}$ after intervention. Of the patients, $11 \mathrm{had}$ residual gradients $>50 \mathrm{mmHg}(14 \%)$. The mean immediate peak systolic gradient was reduced by an average of $63 \%$ after the procedure. A gradient reduction of more than $40 \%$ occurred in 66 patients $(86 \%)$.

The first intervention resulted in an increase of the proportion of patients with grade $>1$ regurgitation by $7 \%$ (from 13 to $20 \%$ ). However, only $3 \%$ of the patients had a post-intervention regurgitation grade $>3$.

A total of four deaths (9\%) were associated with the first intervention. Of these, three deaths happened in patients $<1$ month of age, two after surgical aortic 
Table 2. Patients data before and after intervention.

\begin{tabular}{|c|c|c|c|}
\hline & Total & $\begin{array}{l}\text { Intervention with no } \\
\text { reintervention (group A) }\end{array}$ & $\begin{array}{l}\text { Intervention with } \\
\text { reintervention (group B) }\end{array}$ \\
\hline Number of patients & 77 & 47 & 30 \\
\hline Asymptomatic & $22(29 \%)$ & $11(23 \%)$ & $11(37 \%)$ \\
\hline Symptomatic & $55(71 \%)$ & $36(77 \%)$ & $19(63 \%)$ \\
\hline \multicolumn{4}{|l|}{ Variables measured pre-intervention } \\
\hline Mean peak aortic gradient $(\mathrm{mmHg})$ & $92 \pm 30$ & $94 \pm 32$ & $90 \pm 26$ \\
\hline Peak aortic gradient $>50 \mathrm{mmHg}$ & $75(97 \%)$ & $46(98 \%)$ & $29(97 \%)$ \\
\hline Peak aortic gradient $>60 \mathrm{mmHg}$ & $69(90 \%)$ & $40(85 \%)$ & $29(97 \%)$ \\
\hline Peak aortic gradient $>75 \mathrm{mmHg}$ & $57(74 \%)$ & $34(72 \%)$ & $23(77 \%)$ \\
\hline Mean aortic jet velocity $(\mathrm{m} / \mathrm{s})$ & $4.7 \pm 1.0$ & $4.7 \pm 0.9$ & $4.7 \pm 0.9$ \\
\hline Aortic jet velocity $>4 \mathrm{~m} / \mathrm{s}$ & $41(53 \%)$ & $26(55 \%)$ & $15(50 \%)$ \\
\hline \multicolumn{4}{|l|}{ Aortic regurgitation } \\
\hline Grade $0-1$ & $67(87 \%)$ & $38(81 \%)$ & $29(97 \%)$ \\
\hline Grade 2 & $7(9 \%)$ & $6(13 \%)$ & $1(3 \%)$ \\
\hline Grade 3 & $3(4 \%)$ & $3(6 \%)$ & 0 \\
\hline $\mathrm{Z}$ score LV end-diastolic dimension & 0.12 & $0.13 \pm 2.62$ & $0.11 \pm 2.95$ \\
\hline $\mathrm{Z}$ score LV end-systolic dimension & -0.15 & $-0.39 \pm 0.47$ & $0.23 \pm 0.59$ \\
\hline Z score IV septum & 3.33 & $3.45 \pm 3.03$ & $3.15 \pm 2.03$ \\
\hline $\mathrm{Z}$ score $\mathrm{LV}$ posterior wall thickness & 3.11 & $2.64 \pm 0.35$ & $3.86 \pm 0.44$ \\
\hline $\mathrm{Z}$ score aortic annular index & 0.92 & $1.26 \pm 2.31$ & $0.41 \pm 2.29$ \\
\hline LV ejection fraction $\%$ & 77.4 & $76.4 \pm 12.8$ & $79.0 \pm 14.5$ \\
\hline LV fractional shortening $\%$ & 44.4 & $44.4 \pm 9.2$ & $44.3 \pm 14.7$ \\
\hline Hypertrophy on the ECG & $54(70 \%)$ & $35(75 \%)$ & $19(65 \%)$ \\
\hline \multicolumn{4}{|l|}{ Variables measured post-intervention } \\
\hline $\begin{array}{l}\text { Mean residual peak aortic gradient } \\
(\mathrm{mmHg})\end{array}$ & $35 \pm 20$ & $29 \pm 19$ & $46 \pm 15$ \\
\hline Residual peak aortic gradient $>30 \mathrm{mmHg}$ & $46(60 \%)$ & $18(38 \%)$ & $28(93 \%)$ \\
\hline Residual peak aortic gradient $>50 \mathrm{mmHg}$ & $11(14 \%)$ & $5(11 \%)$ & $6(20 \%)$ \\
\hline \multicolumn{4}{|l|}{ Aortic regurgitation } \\
\hline Grade $0-1$ & $62(81 \%)$ & $41(87 \%)$ & $21(70 \%)$ \\
\hline Grade 2 & $13(17 \%)$ & $6(13 \%)$ & $7(23 \%)$ \\
\hline Grade 3 & $2(3 \%)$ & 0 & $2(7 \%)$ \\
\hline
\end{tabular}

$\mathrm{IV}=$ interventricular; $\mathrm{LV}=$ left ventricular

valvotomy, and one after percutaneous balloon aortic valvuloplasty. Of these three deaths, two occurred in an interval $<30$ days after intervention because of cardiac insufficiency, and one happened 45 days after surgical valvotomy by a cardiac arrest after obstruction of the endotracheal tube. All of them had a severe preoperative aortic stenosis. The fourth death occurred in a 5.5-year-old patient who had severe congestive heart failure at diagnosis and died in an interval $>30$ days after surgical valvotomy.

\section{Long-term results}

Clinical follow-up information, including survival and need for repeat intervention, was available at a mean follow-up of $13.8 \pm 9.1$ years (range 1-431 months, cumulative follow-up of 611 years).

Of the patients who underwent a first intervention, $30(39 \%)$ required a reintervention in a mean interval of $7.6 \pm 5.3$ years (range $0.5-251$ months). A third intervention on the aortic valve was necessary in seven cases $(6 \%)$, and a fourth intervention in two cases
(2\%). Owing to the sample size in what follows only the first reintervention is considered.

The indication for reintervention included restenosis in 17 cases (57\%), aortic regurgitation in two $(7 \%)$, and a combination of aortic stenosis and regurgitation in eight patients $(27 \%)$. All of the 30 patients underwent surgery; none required a repeat balloon dilatation. A Ross procedure was necessary in 19 patients (17\%), an aortic valve replacement in six patients $(15 \%)$, and a surgical aortic valvotomy in five patients $(5 \%)$.

When we evaluate the peak systolic valve gradient after the first procedure, we observe a progression or a recurrence of the stenosis in $39 \%$ of the cases. For example, 11 of the 30 patients (37\%), who had to undergo a reintervention, presented a peak aortic gradient $>75 \mathrm{mmHg}$ before reintervention compared with two patients $(7 \%)$ after first intervention, and $15(50 \%)$ patients had a peak aortic gradient $>50$ $\mathrm{mmHg}$ before reintervention compared with six $(20 \%)$ after first procedure. The mean peak aortic gradient before reintervention was $73 \pm 20 \mathrm{mmHg}$. 


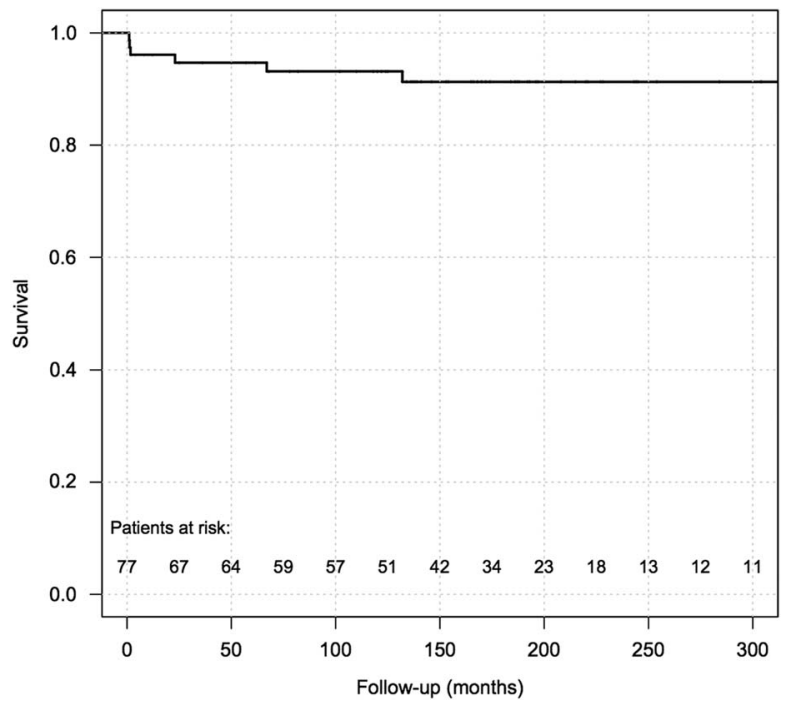

Figure 1.

Kaplan-Meier estimates of survival after first intervention.

A similar effect was documented for the regurgitation after intervention. We observe a significant progression of regurgitation at follow-up, with $40 \%$ of these patients having a regurgitation grade $>1$ before reintervention as compared with $20 \%$ immediately after first procedure. Patients with regurgitation grade 3 increased from $3 \%$ after intervention to $18 \%$ at late follow-up.

Long-term survival of patients with aortic stenosis after first procedure was excellent, with $96 \%$ survival at 1 year, $93 \%$ survival at 10 years, and $91 \%$ at 25 years, respectively (Fig 1). The only two late deaths were related to reintervention. One patient with a moderate aortic stenosis died after cardiac arrest at introduction of anesthesia, and the second one died of cardiac insufficiency by myocardial infarction 60 days after surgical valvotomy reintervention.

The estimated freedom from reintervention was $97,89,75,53$, and $42 \%$, at $1,10,15,20$, and 25 years, respectively (Fig 2 ).

\section{Factors influencing long-term results}

To evaluate possible predictors of repeat intervention after the first procedure, the 77 patients were divided into two groups consisting of 47 patients who did not have a repeat intervention on their aortic valve during the 25 years of follow-up (group A), and 30 patients who did (group B). Comparison of pre- and postintervention characteristics for group A and group B are summarised in Table 2, significant factors are described below. Both univariate and multivariate analyses gave some similar results, suggesting that only increased left ventricular posterior wall

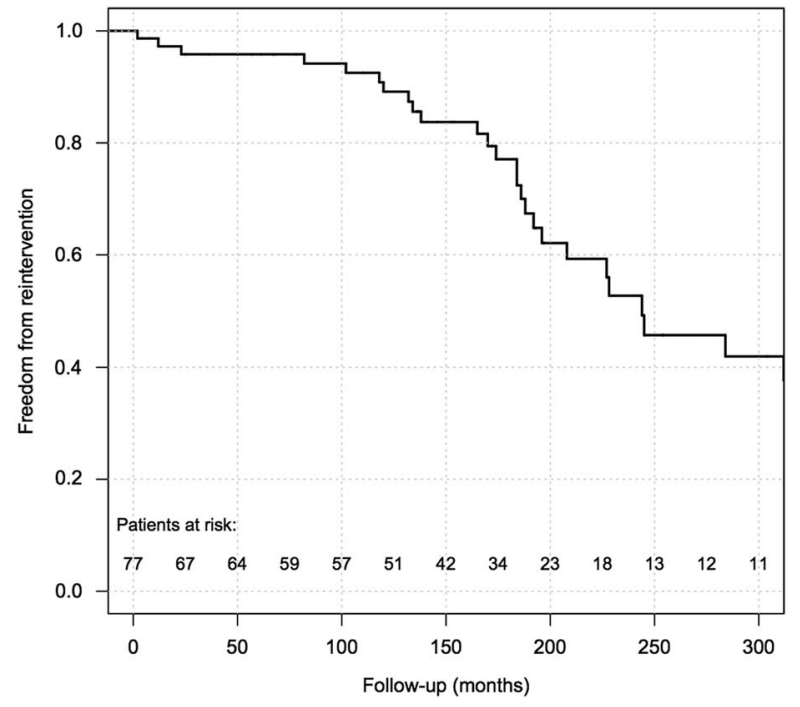

Figure 2.

Kaplan-Meier estimates of freedom from reintervention.

thickness before intervention, balloon valvuloplasty, residual peak aortic gradient, and regurgitation grade $>1$ after the first procedure influenced significantly time to repeat intervention (Table 3).

Patients who had undergone balloon valvuloplasty as the first procedure significantly underwent more repeat intervention than patients who had undergone surgical intervention. Estimated reintervention-free survival after balloon aortic valvuloplasty was 100 , $81,55,16$, and $8 \%$ at $1,10,15,20$, and 25 years, respectively, compared with $96,92,81,67$, and $56 \%$ for patients with no prior balloon valvuloplasty (Fig 3). Aortic regurgitation grade $>1$ after the first procedure independently predicted the chance of repeat intervention. The proportion of patients having a reintervention was twice as high when the aortic regurgitation grade was superior to 1 . The greater the residual peak aortic gradient after procedure, the higher was the risk of repeat intervention. Moreover, a gradient cutoff point of $30 \mathrm{mmHg}$ immediately after intervention was shown to be predictive of reintervention with a sensitivity of $87 \%$ and a specificity of $66 \%$. Interestingly, the rate of reintervention was also influenced by increased left ventricular posterior wall thickness before intervention.

The remaining variables, including gender, age, body surface, bicuspid aortic valve, subvalvular stenosis, dysplastic aortic valve, and surgical aortic valvotomy had no influence on time to repeat intervention, as well as the following pre-intervention values: symptoms, peak aortic gradient, aortic jet velocity, ejection fraction, fractional shortening, aortic regurgitation $>1$, left ventricular end-systolic and end-diastolic diameter, interventricular septum thickness, aortic annulus 
diameter, and hypertrophy signs on the ECG, which were not found to be significant predictors of outcome (Table 4).

Table 3. Variables tested by statistical analysis.

Variables in scope for statistical analysis

Age at diagnosis

Patients with age at diagnosis $<1$ year

Patients with age at diagnosis $<1$ month

Median body length $(\mathrm{cm})$

Median body weight $(\mathrm{kg})$

Gender

Bicuspid aortic valve

Subvalvular stenosis

Dysplastic aortic valve

Balloon aortic valvuloplasty

Surgical aortic valve surgery

Symptomatic

Variables measured pre-intervention

Mean peak aortic gradient $(\mathrm{mmHg})$

Peak aortic gradient $>50 \mathrm{mmHg}$

Peak aortic gradient $>60 \mathrm{mmHg}$

Peak aortic gradient $>75 \mathrm{mmHg}$

Aortic regurgitation pre-intervention grade $>1$

Mean aortic jet velocity $(\mathrm{m} / \mathrm{s})$

$\mathrm{Z}$ score LV end-diastolic dimension

$Z$ score LV end-systolic dimension

$Z$ score IV septum

$\mathrm{Z}$ score LV posterior wall thickness

$\mathrm{Z}$ score aortic annular index

LV ejection fraction \%

LV fractional shortening \%

Hypertrophy on the ECG

Variables measured post-intervention

Mean residual peak aortic gradient $(\mathrm{mmHg})$

Residual peak aortic gradient $>30 \mathrm{mmHg}$

Residual peak aortic gradient $>50 \mathrm{mmHg}$

Aortic regurgitation post-intervention grade $>1$

$\mathrm{IV}=$ interventricular; $\mathrm{LV}=$ left ventricular

\section{Discussion}

We present our experience with 77 consecutive paediatric patients with congenital aortic valve stenosis followed up in our institution, referral centre for $\sim 1$ million inhabitants, during a period of 25 years. Long-term survival after intervention is excellent; however, reintervention is frequently required.

Our immediate results after intervention confirm the findings of previous studies, ${ }^{6,14-20}$ namely, the first intervention was successful with a significant reduction in peak aortic and an immaterial increase in aortic regurgitation of the patients. Mortality rate in our study stood at $8 \%$ compared with other studies. ${ }^{15,21-25}$

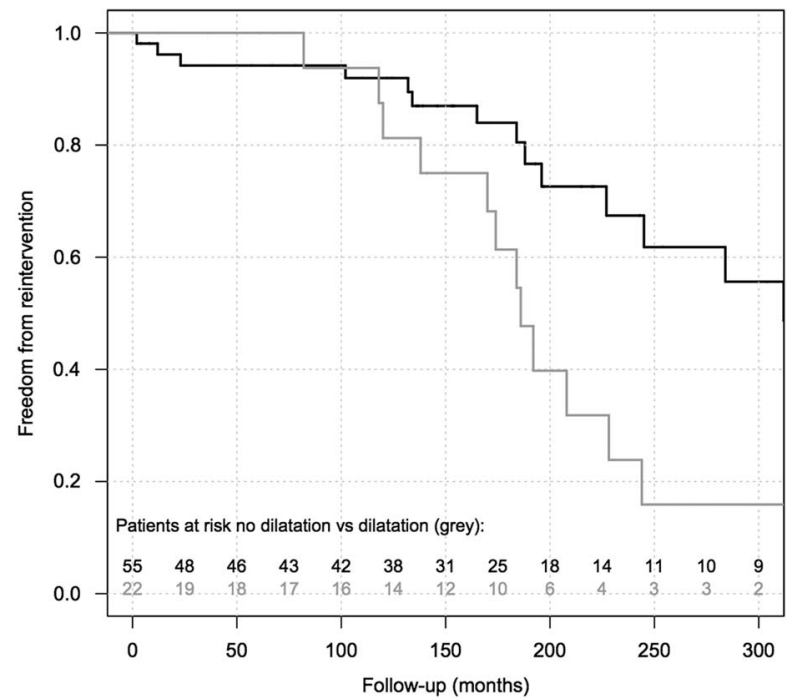

Figure 3.

Kaplan-Meier estimates of freedom from reintervention from patients with prior balloon valvuloplasty compared with patients without prior balloon valvuloplasty.

Table 4. Predictors of reintervention.

\begin{tabular}{|c|c|c|c|c|}
\hline & \multicolumn{2}{|l|}{ Univariate analysis } & \multicolumn{2}{|c|}{ Multivariate analysis } \\
\hline & Odds ratio & p-value & $\mathbf{R}^{2}$ & p-value \\
\hline Mean residual peak aortic gradient $\mathrm{mmHg}$ & & $<0.0001$ & 0.154 & 0.0001 \\
\hline Residual peak aortic gradient $>30 \mathrm{mmHg} * *$ & $12.59(3.74-42.37)$ & $<0.0001$ & 0.216 & $<0.0001$ \\
\hline Aortic regurgitation post-intervention grade $>1$ & $4.2(1.27-13.92)$ & 0.01 & 0.207 & 0.02 \\
\hline Balloon aortic valvuloplasty & $4.27(1.49-12.14)$ & 0.005 & 0.245 & 0.04 \\
\hline Z Score LV posterior wall thickness* & & 0.03 & 0.271 & 0.1 \\
\hline Aortic regurgitation pre-intervention grade $>1 *$ & $0.14(0.02-1.22)$ & 0.04 & 0.287 & 0.20 \\
\hline Patients with age at diagnosis $<1$ year & $2.36(0.91-6.10)$ & 0.07 & & \\
\hline Age at intervention & & 0.07 & & \\
\hline Median body weight $\mathrm{kg}$ & & 0.07 & & \\
\hline Median body length $\mathrm{cm}$ & & 0.09 & & \\
\hline Peak aortic gradient $>60 \mathrm{mmHg} *$ & $5.07(0.59-43.53)$ & 0.10 & & \\
\hline
\end{tabular}

$\mathrm{LV}=$ left ventricular

* Measured before the intervention

**Multivariate analysis also performed independently with the $30 \mathrm{mmHg}$ cut-off 
The long-term survival results are good with a stable survival rate of $91 \%$ up to 25 years and are similar to other studies reporting a 10-year survival of $92-96 \%$. $^{7,21,26-31}$ Yet, the low incidence of sudden death seems to support our selection criteria for early and repeat intervention.

The incidence of repeat intervention in the long term is important. There are several contemporary surgical reports describing excellent results with low reintervention rates (up to $90 \%$ free from reoperation at 10 years post-surgery). ${ }^{20,21,27-30,32,33}$ Our study shows comparable results in the first 10 years after intervention, but thereafter the freedom from reintervention decreases significantly. Over the past 20 years, much improvement has been made in interventional catheterisation and surgery, which should improve long-term results in these patients.

However, these comparisons are of limited value because of the inconsistent criteria used to determine the need for repeat intervention. Further investigation is warranted to optimise patient selection and appropriate criteria for the timing of reintervention.

\section{Balloon valvuloplasty versus surgical valvotomy}

In our study, there was a trend towards more reintervention in the patients who had a prior intervention with balloon valvuloplasty. Interestingly, the need for aortic valve reintervention after balloon dilatation was unrelated to age at the first procedure or to severity at presenting aortic stenosis.

Throughout the literature, we found various studies comparing results of balloon dilatation with surgical valvotomy. ${ }^{3,6-9,20,22,29,30,32,34-36}$ However, these studies have a number of limitations including retrospective analysis, non-randomised patient group, comparisons between different time periods, different lengths of follow-up, and a lack of set criteria for intervention and reintervention. Despite these limitations, and with a lack of prospective randomised trials, these studies concede that the outcomes of balloon dilatation and surgical valvotomy are equivalent and that the type of intervention is not predictive of outcome. ${ }^{6,8,9}$ This is in contrast with our findings that a shorter freedom from reintervention for patients undergoing balloon valvuloplasty is certainly because of a change in practice in our institution, with a more aggressive approach to aortic valve repair for paediatric patients over the last decade. Moreover, the technology of balloon valvuloplasty evolved during the last 25 years, with regard to size of the balloon and the risk of increasing aortic regurgitation, and may also explain this contrasting finding.

However, if a treatment strategy is adopted that uses balloon valvuloplasty as initial palliation instead of initial aortic valve surgery, patients may benefit from at least one less open-heart surgery in their life, thus lowering the risk of reoperation resulting from scar tissue and decreasing the risk of the neurodevelopmental consequences of cardiopulmonary bypass. ${ }^{37}$ Balloon valvuloplasty is also associated with shorter hospital stays and recovery periods as well as lower costs. $6,14,31$

\section{Aortic regurgitation}

As already described in some studies, we identified the presence of more than mild aortic regurgitation immediately after intervention as risk factors for reintervention. ${ }^{20,26,38}$ In addition, the $20 \%$ incidence rate of significant aortic regurgitation immediately after intervention, and the $40 \%$ incidence rate at follow-up, are of concern. The increase in aortic regurgitation over the period of follow-up reflects the progressive nature of this disorder. The observation that the degree of aortic regurgitation increases over time is universal, and is common to all case series, whether related to catheter or surgical intervention. ${ }^{14,20-23,33,39-41}$ In the literature, we observed a 7-19\% increase in the degree of aortic regurgitation directly after intervention, ${ }^{16,20,31,38}$ and a $10-45 \%$ incidence of significant aortic regurgitation at late follow-up. $8,14,23-25,31,34,38,39$

Although risk factors for increasing aortic regurgitation have not been fully defined, it has been speculated that this is an inevitable occurrence because of the intrinsically abnormal morphology of the aortic valve, reflecting the modified natural history of this disorder. This is not surprising, considering that either the balloon of the interventionist, or the scalpel of the surgeon, cause variable splitting of the fused zones of apposition of the leaflets, this being the primary mechanism for valve dysfunction. ${ }^{42}$ Indeed, inspection at surgery shows commissural avulsion, tearing, perforation, extensive scarring, and calcification. ${ }^{434}$ Tear, perforation, or partial detachment could be easily explained by procedure. ${ }^{42}$ Furthermore, blow flow through the aortic valve leads to constant haemodynamic trauma.

Although it has been suggested that aortic regurgitation may be more frequent after balloon dilatation than surgical valvotomy, data from our institution were also tested for these parameters but do not support this view, as described in other studies. ${ }^{8,31}$ At late follow-up, aortic regurgitation increased significantly in both surgically and balloon dilated cohorts.

\section{Residual peak aortic gradient}

Congenital aortic valve stenosis is a progressive lesion and risk of reintervention after initial procedure on aortic valve stenosis is high. ${ }^{20,21,23,33,36,41}$ Most series identify the higher residual gradients or a progressive and 
recurrent systolic pressure gradient after the first procedure as predictors for reintervention. $7,26,31,34,38,40,45$

In our study, the outcome of the first intervention on aortic valve stenosis in terms of immediate gradient reduction is comparable to that reported by others. $^{6,7,15-18,20,25,34,46}$ This attests the efficacy of aortic first intervention in relieving left ventricular outflow tract obstruction and confirms previous reports. However, $14 \%$ of the patients had acute residual gradient of $50 \mathrm{mmHg}$ or greater, and $39 \%$ of the patients showed a progressive or recurrent systolic pressure gradient at late follow-up. Indeed, although in group A the peak aortic gradient after intervention remains low for many years, confirming a favourable and long-lasting success of first intervention in reducing the left ventricular pressure load in this group, in group B a significant increase in residual gradients was documented. Therefore, not surprisingly in our population, and in accordance with the results reported in the literature, ${ }^{47,48}$ most of the reinterventions performed on the aortic valve were because of restenosis or persistent residual gradient.

More precisely, we identified a residual gradient immediately subsequent to the procedure $>30$ $\mathrm{mmHg}$ as a risk factor for reintervention. It confirms the findings of two previous studies. Pedra et $\mathrm{al}^{14}$ found the risk of reintervention as increasing logarithmically for values of $>30 \mathrm{mmHg}$. Galal et al ${ }^{36}$ identified with multivariable stepwise logistic regression analysis an immediate residual gradient of $>30 \mathrm{mmHg}$ as predictor of restenosis. In a third study, Demkow et al ${ }^{38}$ described some similar findings with a residual gradient of $>40 \mathrm{mmHg}$ after the procedure carrying a sixfold increase in relative risk for reintervention for restenosis. Although these studies have demonstrated similar outcomes and associated risk function, systematic comparison of different series are of limited value because of heterogeneous population, non-contemporary timeframes, lack of uniformity in defining restenosis, and variables criteria to determine the need of reintervention.

\section{Left ventricular posterior wall thickness}

Interestingly, we also found an initial echocardiographic factor as predictor of reintervention. The increased left ventricular posterior wall thickness before first intervention was independently associated with shorter freedom from reintervention. In the literature, we did not find a study highlighting these relationships. To find further implication of this parameter, it would be necessary to conduct a prospective randomised study.

\section{Study limitations}

There are several limitations to this study. The primary limitation is its retrospective design and the extended enrolment period, a process that may limit the applicability of our findings. For example, there has been substantial evolution in balloon technology, which may have influenced both technical variables and outcomes. Similarly, the patients have not been randomised in one group or the other, and thus the responsibility of intervention with balloon valvuloplasty or surgical valvotomy was incumbent on the surgeon or cardiologist and was not necessarily consistent over the course of the study period. In addition, this analysis is from a single institution, and the number of patients is relatively small and heterogeneous, and thus the results may not necessarily be generalisable to all patients with congenital aortic valve stenosis.

\section{Conclusion}

This study confirms that first intervention is a safe and effective procedure to provide a significant acute relief of congenital aortic stenosis. Owing to the progressive nature of this pathology and the palliative incidence of first intervention, sooner or later a reintervention would be necessary. Factors increasing the risk of reintervention include increased left ventricular posterior wall thickness pre-intervention, prior balloon valvuloplasty, higher residual peak systolic valve gradient, and more than mild regurgitation postintervention. The study highlights that long-term or even life follow-up is recommended for these patients. Our findings should inform and help the specialist in his decision making for the long-term follow-up of congenital aortic valve stenosis.

\section{Acknowledgement}

The authors gratefully acknowledge the kind collaboration of the Cardiovascular Surgery and Pediatric Cardiology staff of the University Hospital of Lausanne.

\section{Financial Support}

This research received no specific grant from any funding agency, commercial, or not-for-profit sectors.

\section{Conflicts of Interest}

None.

\section{Ethical Standards}

The authors assert that all procedures contributing to this work comply with the ethical standards of the relevant national guidelines on human experimentation and with the Helsinki Declaration of 1975, as revised in 2008, and has been approved by the institutional committees (Prof. M. Burnier, President 
of the ethical commission on human experimentation (VD), 1011 Lausanne).

\section{References}

1. Stark JF, de Leval MR, Tsang VT. Surgery for Congenital Heart Defects, 2nd edn. WB Saunders, Philadelphia, 1994: 85-95.

2. Kouchoukos NT, Doty DB, Hanley F, et al. Kirklin/Barratt-Boyes Cardiac surgery, 3rd edn. Churchill Livingstone, Philadelphia, 2003: 1266-1307.

3. Keane JF, Driscoll DJ, Gersony WM, et al. Second natural history study of congenital heart defects. Results of treatment of patients with aortic valvar stenosis. Circulation 1993; 87: I16-I27.

4. Lillehei CW, Dewall RA, Gott VL, Varco RL. The direct vision correction of calcific aortic stenosis by means of a pump-oxygenator and retrograde coronary sinus perfusion. Dis Chest 1956; 30: 123-132.

5. Lababidi Z. Aortic balloon valvuloplasty. Am Heart J 1983; 106: 751-752.

6. Gatzoulis MA, Rigby ML, Shinebourne EA, Redington AN. Contemporary results of balloon valvuloplasty and surgical valvotomy for congenital aortic stenosis. Arch Dis Child 1995; 73: 66-69.

7. Reich O, Tax P, Marek J, et al. Long term results of percutaneous balloon valvoplasty of congenital aortic stenosis: independent predictors of outcome. Heart 2004; 90: 70-76.

8. Justo RN, McCrindle BW, Benson LN, Williams WG, Freedom RM, Smallhorn JF. Aortic valve regurgitation after surgical versus percutaneous balloon valvotomy for congenital aortic valve stenosis. Am J Cardiol 1996; 77: 1332-1338.

9. McCrindle BW, Blackstone EH, Williams WG, et al. Are outcomes of surgical versus transcatheter balloon valvotomy equivalent in neonatal critical aortic stenosis? Circulation 2001; 104: I152-I158.

10. Haycock GB, Schwartz GJ, Wisotsky DH. Geometric method for measuring body surface area: a height-weight formula validated in infants, children, and adults. J Pediatr 1978; 93: 62-66.

11. Kampmann C, Wiethoff CM, Wenzel A, et al. Normal values of $\mathrm{M}$ mode echocardiographic measurements of more than 2000 healthy infants and children in central Europe. Heart 2000; 83: $667-672$.

12. Otto CM. Valvular aortic stenosis: disease severity and timing of intervention. J Am Coll Cardiol 2006; 47: 2141-2151.

13. Bonow RO, Carabello BA, Chatterjee $\mathrm{K}$, et al. Focused update incorporated into the ACC/AHA 2006 guidelines for the management of patients with valvular heart disease: a report of the American College of Cardiology/American Heart Association Task Force on Practice Guidelines. Circulation 2008; 118: e523-e661.

14. Pedra CA, Sidhu R, McCrindle BW, et al. Outcomes after balloon dilation of congenital aortic stenosis in children and adolescents. Cardiol Young 2004; 14: 315-321.

15. Vogel M, Benson LN, Burrows P, Smallhorn JF, Freedom RM. Balloon dilatation of congenital aortic valve stenosis in infants and children: short term and intermediate results. Br Heart J 1989; 62: $148-153$.

16. O'Connor BK, Beekman RH, Rocchini AP, Rosenthal A. Intermediate-term effectiveness of balloon valvuloplasty for congenital aortic stenosis. A prospective follow-up study. Circulation 1991; 84: 732-738.

17. Rosenfeld HM, Landzberg MJ, Perry SB, Colan SD, Keane JF, Lock JE. Balloon aortic valvuloplasty in the young adult with congenital aortic stenosis. Am J Cardiol 1994; 73: 1112-1117.

18. Shaddy RE, Boucek MM, Sturtevant JE, Ruttenberg HD, Orsmond GS. Gradient reduction, aortic valve regurgitation and prolapse after balloon aortic valvuloplasty in 32 consecutive patients with congenital aortic stenosis. J Am Coll Cardiol 1990; 16: 451-456.
19. Knirsch W, Berger F, Harpes P, Kretschmar O. Balloon valvuloplasty of aortic valve stenosis in childhood: early and medium term results. Clin Res Cardiol 2008; 97: 587-593.

20. Moore P, Egito E, Mowrey H, Perry SB, Lock JE, Keane JF. Midterm results of balloon dilation of congenital aortic stenosis: predictors of success. J Am Coll Cardiol 1996; 27: 1257-1263.

21. Hawkins JA, Minich LL, Tani LY, et al. Late results and reintervention after aortic valvotomy for critical aortic stenosis in neonates and infants. Ann Thorac Surg 1998; 65: 1758-1762.

22. McCrindle BW. Independent predictors of immediate results of percutaneous balloon aortic valvotomy in children. Am J Cardiol 1996; 77: 286-293.

23. Bauer EP, Schmidli J, Vogt PR, von Segesser LK, Turina MI. Valvotomy for isolated congenital aortic stenosis in children: prognostic factors for outcome. Thorac Cardiovasc Surg 1992; 40: 334-339.

24. Kuhn MA, Latson LA, Cheatham JP, Fletcher SE, Foreman C. Management of pediatric patients with isolated valvar aortic stenosis by balloon aortic valvuloplasty. Cathet Cardiovasc Diagn 1996; 39: 55-61.

25. DeBoer DA, Robbins RC, Maron BJ, McIntosh CL, Clark RE. Surgery Branch, National Heart, Lung and Blood Institute, National Institutes of Health, Bethesda, Maryland 20892. Late results of aortic valvotomy for congenital valvar aortic stenosis. Ann Thorac Surg 1990; 50: 69-73.

26. Brown DW, Dipilato AE, Chong EC, Lock JE, McElhinney DB. Aortic valve reinterventions after balloon aortic valvuloplasty for congenital aortic stenosis intermediate and late follow-up. J Am Coll Cardiol 2010; 56: 1740-1749.

27. Jindal RC, Saxena A, Juneja R, Kothari SS, Shrivastava S. Long-term results of balloon aortic valvulotomy for congenital aortic stenosis in children and adolescents. J Heart Valve Dis 2000; 9: 623-628.

28. Lambert V, Obreja D, Losay J, et al. Long-term results after valvotomy for congenital aortic valvar stenosis in children. Cardiol Young 2000; 10: 590-596.

29. Alexiou C, Chen Q, Langley SM, et al. Is there still a place for open surgical valvotomy in the management of aortic stenosis in children? The view from Southampton. Eur J Cardiothorac Surg 2001; 20: 239-246.

30. Detter C, Fischlein T, Feldmeier C, Nollert G, Reichart B. Aortic valvotomy for congenital valvular aortic stenosis: a 37-year experience. Ann Thorac Surg 2001; 71: 1564-1571.

31. Fratz S, Gildein HP, Balling G, et al. Aortic valvuloplasty in pediatric patients substantially postpones the need for aortic valve surgery: a single-center experience of 188 patients after up to 17.5 years of follow-up. Circulation 2008; 117: 1201-1206.

32. Kugelmeier J, Egloff L, Real F, Rothlin M, Turina M, Senning A. Congenital aortic stenosis. Early and late results of aortic valvulotomy. Thorac Cardiovasc Surg 1982; 30: 91-95.

33. Ettedgui JA, Tallman-Eddy T, Neches WH, et al. Long-term results of survivors of surgical valvotomy for severe aortic stenosis in early infancy. J Thorac Cardiovasc Surg 1992; 104: 1714-1720.

34. Balmer C, Beghetti M, Fasnacht M, Friedli B, Arbenz U. Balloon aortic valvoplasty in paediatric patients: progressive aortic regurgitation is common. Heart 2004; 90: 77-81.

35. Hsieh KS, Keane JF, Nadas AS, Bernhard WF, Castaneda AR. Long-term follow-up of valvotomy before 1968 for congenital aortic stenosis. Am J Cardiol 1986; 58: 338-341.

36. Galal O, Rao PS, Al-Fadley F, Wilson AD. Follow-up results of balloon aortic valvuloplasty in children with special reference to causes of late aortic insufficiency. Am Heart J 1997; 133: 418-427.

37. Bellinger DC, Jonas RA, Rappaport LA, et al. Developmental and neurologic status of children after heart surgery with hypothermic circulatory arrest or low-flow cardiopulmonary bypass. $\mathrm{N}$ Engl J Med 1995; 332: 549-555.

38. Demkow M, Ruzyllo W, Ksiezycka E, et al. Long-term follow-up results of balloon valvuloplasty for congenital aortic stenosis: predictors of late outcome. J Invasive Cardiol 1999; 11: 220-226. 
39. Weidman WH. Second natural history study of congenital heart defects. Circulation 1993; 87: I1-I3.

40. McElhinney DB, Lock JE, Keane JF, Moran AM, Colan SD. Left heart growth, function, and reintervention after balloon aortic valvuloplasty for neonatal aortic stenosis. Circulation 2005; 111: $451-458$.

41. Chartrand CC, Saro-Servando E, Vobecky JS. Long-term results of surgical valvuloplasty for congenital valvar aortic stenosis in children. Ann Thorac Surg 1999; 68: 1356-1359.

42. Waller BF, McKay C, VanTassel JW, Taliercio C, Howard J, Green F. Catheter balloon valvuloplasty of stenotic aortic valves. Part I: anatomic basis and mechanisms of balloon dilation. Clin Cardiol 1991; 14: 836-846.

43. Phillips RR, Gerlis LM, Wilson N, Walker DR. Aortic valve damage caused by operative balloon dilatation of critical aortic valve stenosis. Br Heart J 1987; 57: 168-170.
44. Bacha EA, Satou GM, Moran AM, et al. Valve-sparing operation for balloon-induced aortic regurgitation in congenital aortic stenosis. J Thorac Cardiovasc Surg 2001; 122: 162-168.

45. Jindal RC, Saxena A, Juneja R, Kothari SS, Shrivastava S. Longterm results of balloon aortic valvulotomy for congenital aortic stenosis in children and adolescents. J Heart Valve Dis 2000; 9: 623-628.

46. Lababidi Z, Wu JR, Walls JT. Percutaneous balloon aortic valvuloplasty: results in 23 patients. Am J Cardiol 1984; 53: 194-197.

47. Satou GM, Perry SB, Lock JE, Piercey GE, Keane JF. Repeat balloon dilation of congenital valvar aortic stenosis: immediate results and midterm outcome. Catheter Cardiovasc Interv 1999; 47: $47-51$.

48. Shim D, Lloyd TR, Beekman RH III. Usefulness of repeat balloon aortic valvuloplasty in children. Am J Cardiol 1997; 79: $1141-1143$. 